\title{
Reduction of Dislocation Densities of Ge Layers Grown on Si Substrates by Using Microwave Plasma Heating and Fabrication of High Hole Mobility MOSFETs on Ge Layers
}

\section{Hiroki Nakaie1, Tetsuji Arai', Chiaya Yamamoto', Keisuke Arimoto', Junji Yamanaka', Kiyokazu Nakagawa1, Toshiyuki Takamatsu²}

${ }^{1}$ Interdisciplinary Graduate School of Medicine and Engineering, University of Yamanashi, Kofu, Japan

${ }^{2}$ SST Inc., Yachiyo, Japan

Email: g15df003@yamanashi.ac.jp

How to cite this paper: Nakaie, H., Arai, T., Yamamoto, C., Arimoto, K., Yamanaka, J., Nakagawa, K. and Takamatsu, T. (2017) Reduction of Dislocation Densities of Ge Layers Grown on Si Substrates by Using Microwave Plasma Heating and Fabrication of High Hole Mobility MOSFETs on Ge Layers. Journal of Materials Science and Chemical Engineering, 5, 42-47.

http://dx.doi.org/10.4236/msce.2017.51006

Received: September 24, 2016

Accepted: January 1, 2017

Published: January 4, 2017

\begin{abstract}
We have developed a microwave plasma heating technique to rapidly heat the transition metal. $\mathrm{W} / \mathrm{SiO}_{2}$ layers were deposited on $\mathrm{Ge} / \mathrm{Si}$ heterostructures. By heating the $\mathrm{W}$, dislocations in Ge layers originated from lattice mismatch between $\mathrm{Ge}$ and $\mathrm{Si}$ crystals were reduced drastically. We have fabricated pMOSFETs on Ge/Si substrates and realized higher mobility of about $380 \mathrm{~cm}^{2} /$ Vs than that of Si p-MOSFET.
\end{abstract}

\section{Keywords}

Microwave Plasma Heating, High Hole Mobility, Ge on Si

\section{Introduction}

Since $\mathrm{Ge}$ is a high-mobility material compared to $\mathrm{Si}$, has been attracting attention as the next generation of devices [1] [2] [3] [4]. However, since the Ge material has low thermal conductivity, devices fabricated on bulk Ge substrates have low performance due to heat during device operation. And they are not suitable to high-speed operation because Ge material has 1000 times higher intrinsic carrier concentration than that of Si material and parasitic capacitance is also high. To overcome these problems, we grow epitaxially very thin Ge layers on Si substrates. Since Si and Ge crystal have about $4 \%$ of lattice mismatch, dislocations are in Ge layers [5] [6].

In this paper, we report that dislocations in $\mathrm{Ge}$ layers of $\mathrm{Ge} / \mathrm{Si}$ heterostructures can bedrastically reduced using new heating method, which can enable us 
to heat transition metals selectively and rapidly. We also fabricated p-MOSFET on Ge layer which was heated by our developed method and demonstrated about 2 times higher carrier mobility than that of Si p-MOSFET.

\section{Experimental Methods}

\subsection{Sample Preparation}

We grew epitaxially $10 \mathrm{~nm}$ Si buffer layers on $\mathrm{n}-\mathrm{Si}(100)$ substrates at $600^{\circ} \mathrm{C}$. Then, $300 \mathrm{~nm}-\mathrm{Ge}$ layers were grown on Si layers at the low temperature of $300^{\circ} \mathrm{C}$ to avoid island growth. Then, $150 \mathrm{~nm}-\mathrm{SiO}_{2}$ films were deposited at $300^{\circ} \mathrm{C}$ by plasma CVD and successively $100 \mathrm{~nm}-\mathrm{W}$ films were deposited at room temperature by RF sputtering.

\subsection{Microwave Plasma Heating}

We have developed microwave plasma heating method. This method enables us to heat transition metals selectively by exposing them to hydrogen plasma. Apparatus has four components: a reaction chamber, a $2.45 \mathrm{GHz}$ microwave generator, a gas flow control unit, and a rotary pump evacuation system [7].

In all the experiments, input microwave power is $1000 \mathrm{~W}$, hydrogen gas flow rate is $5 \mathrm{sccm}$, and pressure is $30 \mathrm{~Pa}$. Figure 1 shows a typical temperature profile when $\mathrm{W}$ film deposited on Ge layer was exposed to hydrogen microwave plasma and the peek temperature was $800^{\circ} \mathrm{C}$. We prepared the samples by changing the plasma exposure time, and the peek values of temperature profiles were from $700^{\circ} \mathrm{C}$ to $900^{\circ} \mathrm{C}$.

\subsection{MOSFET Fabrication}

For MOSFET fabrication, $10 \mathrm{~nm}$-Si buffer layers were grown on $\mathrm{n}$-Si substrate using MBE apparatus at $600^{\circ} \mathrm{C}$. Next, $40 \mathrm{~nm}$-Ge layers were grown at $300^{\circ} \mathrm{C} .5$ $\mathrm{nm}-\mathrm{Si}$ cap films were grown at $300^{\circ} \mathrm{C}$. Then, $150 \mathrm{~nm}-\mathrm{SiO}_{2}$ films were deposited at $300^{\circ} \mathrm{C}$ by plasma CVD and successively $100 \mathrm{~nm}-\mathrm{W}$ films were deposited at room temperature by RF sputtering. We heated these samples by the method.

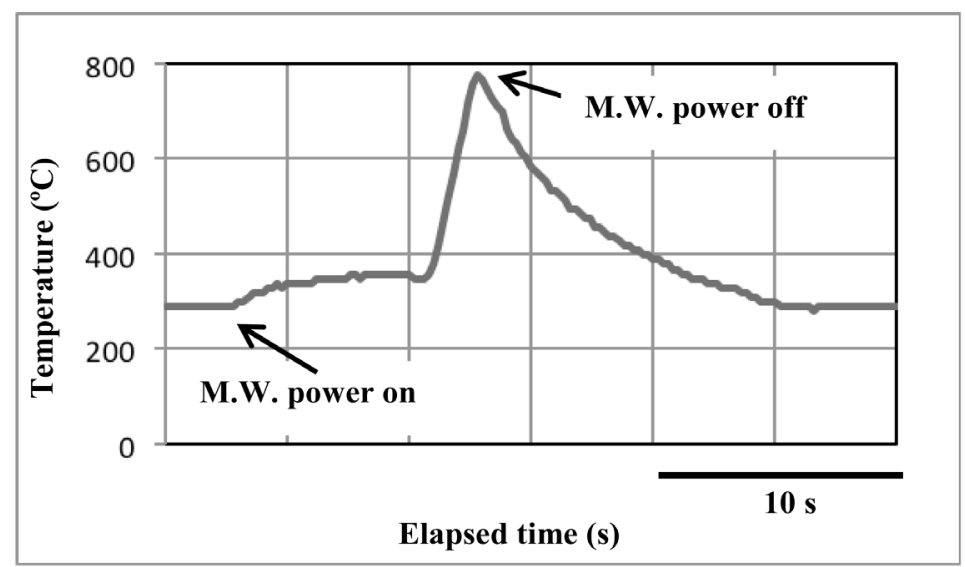

Figure 1. Temperature profile of sample exposed to hydrogen microwave plasma. 
The peek values of temperature profiles were around $800^{\circ} \mathrm{C}$. After removing $\mathrm{W} / \mathrm{SiO}_{2}$ layers, we fabricate MOSFETs using conventional device fabrication processes on $5 \mathrm{~nm}-\mathrm{Si} / 40 \mathrm{~nm}-\mathrm{Ge} / \mathrm{n}-\mathrm{Si}$ substrates. BF2 ions were implanted in source and drain regions at the accelerating voltage of $40 \mathrm{kV}$ with the dose of $1.0 \times$ $10^{15} / \mathrm{cm}^{2}$. The gate insulator was plasma $\mathrm{CVD} \mathrm{SiO}_{2}$.

\section{Results and Discussion}

\subsection{Optimization of Heating Conditions}

We observed microstructures of Ge layers by TEM and STEM. Figure 2 shows a TEM image of before the heat treatment. The Ge layer has many dislocations. Figure 3 shows the results of STEM-EDX. Ge layers were grown on Si substrate without mixing between $\mathrm{Ge}$ and $\mathrm{Si}$ atoms. Figure 4 shows a STEM image of the sample heated up to $900^{\circ} \mathrm{C}$. It can be seen that $\mathrm{Si}$ and $\mathrm{Ge}$ atoms are mixed. Figure 5 and Figure 6 are STEM images of the sample sheated up to $800^{\circ} \mathrm{C}$ and $700^{\circ} \mathrm{C}$, respectively. Mixing between $\mathrm{Si}$ and Ge layers are not observed. In addition, we confirmed using STEM-EDX that no mixing occurred. Figure 7 is a TEM image of the sample heated up to $700^{\circ} \mathrm{C}$. It is seen that dislocations in the Ge layer is drastically decreased.

The heat treatment can reduce dislocations when the peek temperature is from $700^{\circ} \mathrm{C}$ to $800^{\circ} \mathrm{C}$, and the mixing between $\mathrm{Si}$ and Ge layers do not occur.

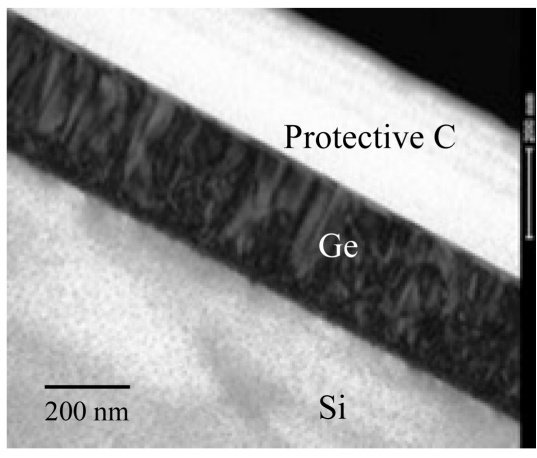

Figure 2. Cross sectional TEM image of as grown sample.

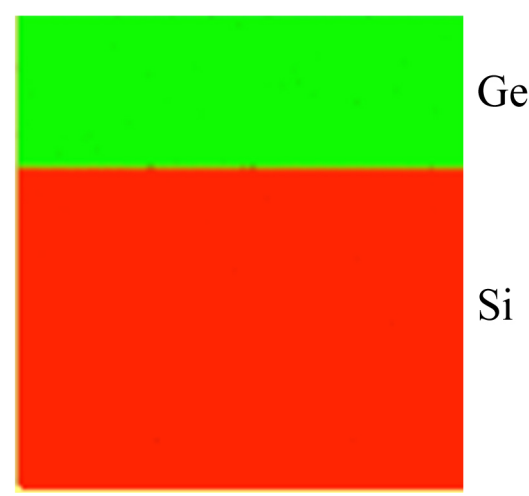

Figure 3. EDX mapping images of $\mathrm{Si}$ and $\mathrm{Ge}$ elements of as grown sample. 


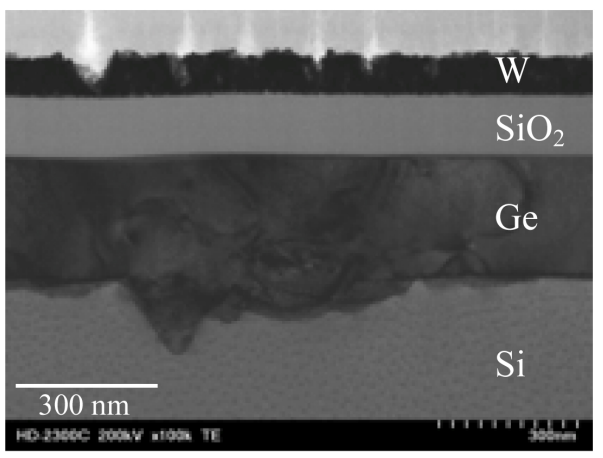

Figure 4. Cross sectional STEM image of sample heated up to $900^{\circ} \mathrm{C}$.

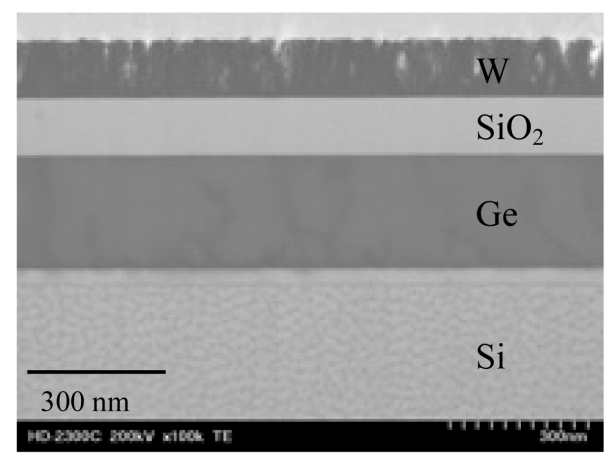

Figure 5. Cross sectional STEM image of sample heated up to $800^{\circ} \mathrm{C}$.

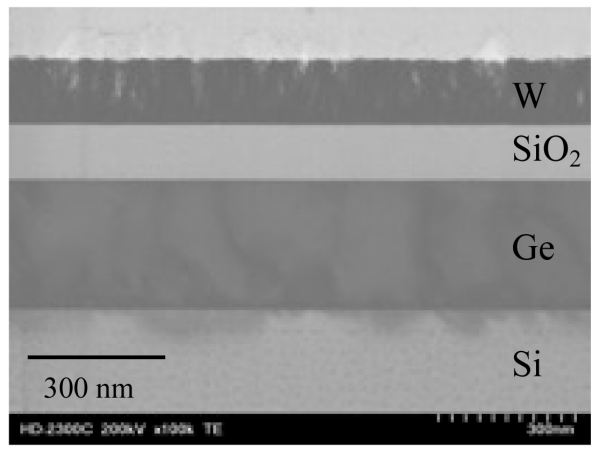

Figure 6. Cross sectional STEM image of sample heated up to $700^{\circ} \mathrm{C}$.

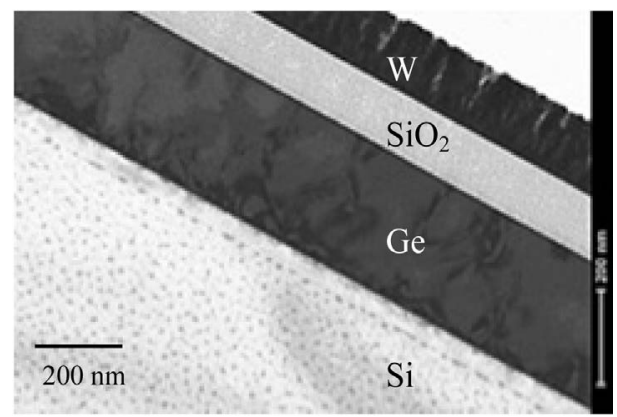

Figure 7. Cross sectional TEM image of sample heated up to $700^{\circ} \mathrm{C}$. 


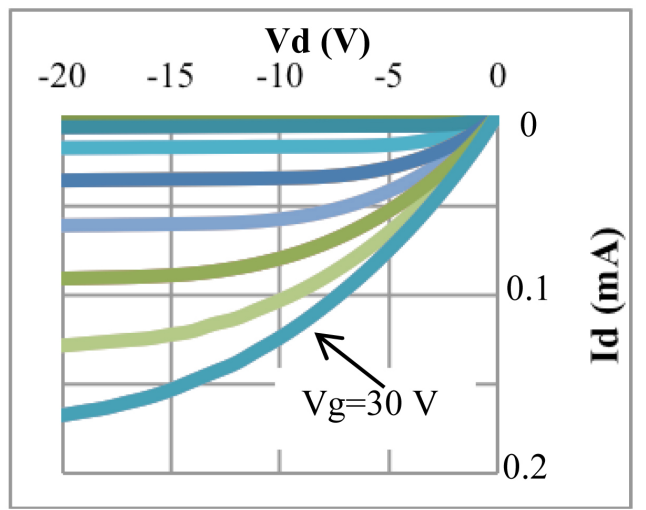

Figure 8. Id-Vd curves of sample which was not heated.

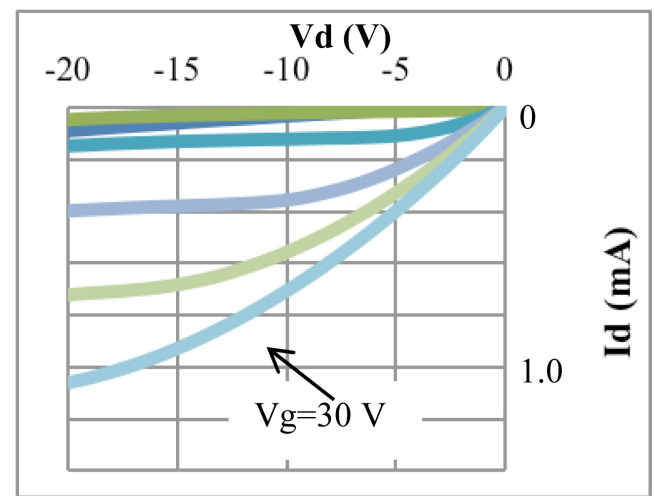

Figure 9. Id-Vd curves of sample heated up to $750^{\circ} \mathrm{C}$.

\subsection{MOS FET Fabrication}

Figure 8 and Figure 9 show Id-Vg characteristic of the samples which was not heated and was heated up to $750^{\circ} \mathrm{C}$, respectively. Device dimensions are $100 \mu \mathrm{m}$ of a channel length and $150 \mu \mathrm{m}$ of a channel width. The gate voltage was changed from $10 \mathrm{~V}$ to $-30 \mathrm{~V}$ with $4 \mathrm{~V}$ increment. The heated sample has one order higher current at the same gate voltage. Effective hole mobility was derived using the split $\mathrm{C}-\mathrm{V}$ method. We obtain 2 times higher the mobility $\left(380 \mathrm{~cm}^{2} / \mathrm{Vs}\right)$ than that of Si p-MOSFET $\left(200 \mathrm{~cm}^{2} / \mathrm{Vs}\right)$.

\section{Summary}

We have developed a microwave plasma heating technique to rapidly heat the transition metal. $\mathrm{W} / \mathrm{SiO}_{2}$ layers were deposited on $\mathrm{Ge} / \mathrm{Si}$ heterostructures. The heat treatment can reduce dislocations when the peek temperature is from $700^{\circ} \mathrm{C}$ to $800^{\circ} \mathrm{C}$, and the mixing between $\mathrm{Si}$ and Ge layers do not occur. We have fabricated p-MOSFETs on $\mathrm{Ge} / \mathrm{Si}$ substrates heated up to $750^{\circ} \mathrm{C}$ and realized higher mobility of about $380 \mathrm{~cm}^{2} / \mathrm{Vs}$ than that of Si p-MOSFET.

\section{References}

[1] Lee, C.H., Nishimura, T., Tabata, T., Wang, S.K., Nagashio, K., Kita, K. and Tori- 
umi, A. (2010) Ge MOSFETs Performance: Impact of Ge Interface Passivation. 2010 IEEE International Electron Devices Meeting (IEDM), 18-1. https://doi.org/10.1109/iedm.2010.5703384

[2] Maeda, T., Ikeda, K., Nakaharai, S., Tezuka, T., Sugiyama, N., Moriyama, Y. and Takagi, S. (2006) Thin-Body Ge-on-Insulator p-Channel MOSFETs with Pt Germanide Metal Source/Drain. Thin Solid Films, 508, 346-350. https://doi.org/10.1016/j.tsf.2005.07.339

[3] Kamata, Y. (2008) High-k/Ge MOSFETs for Future Nanoelectronics. Materials Today, 11, 30-38. https://doi.org/10.1016/S1369-7021(07)70350-4

[4] Lee, M.L., Leitz, C.W., Cheng, Z., Antoniadis, D.A. and Fitzgerald, E.A. (2002) Strained Ge Channel p-Type Metal-Oxide-Semiconductor Field-Effect Transistors Grown on Siâ â xGex/Si Virtual Substrates.

[5] Luan, H.C., Lim, D.R., Lee, K.K., Chen, K.M., Sandland, J.G., Wada, K. and Kimerling, L.C. (1999) High-Quality Ge Epilayers on Si with Low Threading-Dislocation Densities. Applied Physics Letters, 75, 2909-2911. https://doi.org/10.1063/1.125187

[6] Currie, M.T., Samavedam, S.B., Langdo, T.A., Leitz, C.W. and Fitzgerald, E.A. (1998) Controlling Threading Dislocation Densities in Ge on Si Using Graded SiGe Layers and Chemical-Mechanical Polishing. Applied Physics Letters, 72, 1718-1720. https://doi.org/10.1063/1.121162

[7] Arai, T., Nakaie, H., Kamimura, K., Nakamura, H., Ariizumi, S., Ashizawa, S. and Takamatsu, T. (2016) Selective Heating of Transition Metal Usings Hydrogen Plasma and Its Application to Formation of Nickel Silicide Electrodes for Silicon Ultralarge-Scale Integration Devices. Journal of Materials Science and Chemical Engineering, 4, 29. https://doi.org/10.4236/msce.2016.41006

Submit or recommend next manuscript to SCIRP and we will provide best service for you:

Accepting pre-submission inquiries through Email, Facebook, LinkedIn, Twitter, etc. A wide selection of journals (inclusive of 9 subjects, more than 200 journals)

Providing 24-hour high-quality service

User-friendly online submission system

Fair and swift peer-review system

Efficient typesetting and proofreading procedure

Display of the result of downloads and visits, as well as the number of cited articles

Maximum dissemination of your research work

Submit your manuscript at: http://papersubmission.scirp.org/

Or contact msce@scirp.org 